\title{
The national politics of educational advocacy in the context of global governance: International funding and support for civil society engagement in Cambodia
}

-- Forthcoming in Compare: A Journal of Comparative and International Education --

\author{
D. Brent Edwards Jr. \\ University of Hawai'i \\ Willian C. Brehm \\ Waseda Institute for Advanced Study \\ Waseda University \\ Inga Storen \\ University of Oxford
}

\begin{abstract}
This paper examines the Civil Society Education Fund's (CSEF) impact on the NGO Education Partnership (NEP) in Cambodia. With financial backing from the World Bank and the Fast Track Initiative, the CSEF is an initiative that is managed internationally by the Global Campaign for Education. Its goal is to help national networks of non-governmental organizations participate in education decision-making and to serve as a watchdog for progress related to internationally agreed upon goals. Through the CSEF, the deployment of various strategies, and other external factors, NEP was able to able to achieve recognition, legitimacy, and influence at the national level. However, NEP has had to balance working with the state and working for the state. This case study highlights strategies used by civil society actors to engage state actors, the efficacy of international support, and the conflicts inherent in both.
\end{abstract}

Keywords: Cambodia, Global Campaign for Education, Civil Society, Advocacy, Global Governance, Education Politics, Non-governmental organizations, Education for All 


\section{The national politics of educational advocacy in the context of global governance: International funding and support for civil society engagement in Cambodia}

\section{Introduction}

This paper explores the way in which the Global Campaign for Education (GCE) has impacted national level civil society organizations (CSOs) through its Civil Society Education Fund (CSEF). Since 1999, GCE has campaigned for specific education targets, organized loose social movement networks, and trained member organizations (Mundy, 2012). ${ }^{1}$ In June 2015, CSEF membership comprised 4,302 organizations, including national coalitions of education-related NGOs and international and regional organizations, and worked in 55 countries (CSEF, 2015, p. 4, 7). In 2009, GCE began CSEF to support national civil society coalitions in 65 countries with USD \$17.6 million in funding from the Fast Track Initiative (FTI). ${ }^{2}$ The goal of the program was to "fully engage in the development of education sector programmes with government and donors, and track the progress of national governments and local donor groups in working towards the [Education for All] (EFA) goals" (Mundy, 2012, p. 26). Despite the promise of this program, little is known about its operations, successes, or failures.

This paper responds to this lack of knowledge around the CSEF. We do this by presenting the results of a case study on the CSEF contributions to the work of Cambodia's national coalition of education-related nongovernmental organizations (NGOs) - known as the NGO Education Partnership (NEP) — during the years 2009-2012 (Edwards, 2012). In analyzing the case of NEP, we seek to address how and with what outcomes and impact civil society can act strategically to affect education politics and policymaking through the use of CSEF support. We are interested in the micro-politics of how NEP found a "seat" at the proverbial decisionmaking table of education governance and in the kind of impact it has had in this arena. We are also interested in negative outcomes such recognition and legitimacy provided by the state may have on NEPs own goals. Illuminating these issues can provide valuable insights both into the strategies of civil society policy engagement with actors from government and international organizations as well as into the conditions under which civil society can contribute to policy and politics even in the face of significant challenges. As will be argued, these insights are valuable on multiple levels, as NGOs are striving to influence and to support the direction and implementation of the education agenda globally, nationally, and locally.

The paper is structured into four sections. The first section discusses previous experience documented in the literature related to civil society and educational advocacy. This section also presents our analytic framework for understanding civil society engagement through the CSEF,

\footnotetext{
${ }^{1}$ GCE emerged in 1999 from the work of several influential international nongovernmental organizations, including Oxfam, Action Aid, Global March for Labour, and Education International. It has been labeled "the biggest and most active civil society network advocating for EFA" (Verger \& Novelli, 2012, p. 2).

${ }^{2}$ The Education for All FTI was launched in 2002 to encourage low-income countries to reach the Millennium Development Goal of achieving universal primary education. The World Bank played an integral part in FTI's conception and implementation. Over 30 donor agencies support the program, including UNESCO and UNICEF. In 2012, FTI changed its name to Global Partnership for Education (GPE) and underwent an elaborate restructuring that entailed inclusion of civil society members on the its Board of Directors. GPE currently partners with 60 developing nations.
} 
in addition to characterizing the context of civil society engagement in Cambodia. In section three, we outline our methods used for data collection and analysis. The majority of the paper is dedicated to a description of findings (section four), as well as discussion of implications of the study (section five).

\section{Civil society and education advocacy: Previous experience, analytical framework, and Cambodian context \\ 2.1 Previous experience}

Research on education advocacy has increased in conjunction with the rise of civil society advocacy in education during the late 1990s and 2000s, both nationally and transnationally. ${ }^{3}$ Advocacy during this time has been driven by - though not necessarily restricted to - the internationally agreed upon targets for education contained in the EFA initiative and the Millennium Development Goals (Verger \& Novelli, 2012). Much of the research on educational advocacy has addressed the nature, role, and impact of civil society (e.g., Hoppers, 2009; Kamat, 2004; Mundy, Haggerty, Sivasubramaniam, Cherry, \& Maclure, 2010; Mundy \& Murphy, 2001; Rappleye, 2011; Strutt \& Kepe, 2010).

The impact of civil society on education policymaking can be studied by examining the engagement and micro-politics of CSOs. ${ }^{3}$ The history of each organization's emergence affects the ways in which it operates and is accepted (or not) by other actors in educational governance. In some cases, such as Ecuador and Indonesia, formal CSOs emerged as social movements responding to various national-level education reform efforts (Hoop, 2012; Hilgersom, 2012). In other cases, such as in Zambia, CSOs where organized through international interlocutors (Van Der Plaat, 2012a).

A distinction can be made between CSOs in the Global North and South. Bendaña (2006), for example, notes that while "social movements" is a label more commonly associated with the Global South, the term "NGO" tends to be used in the North. Moreover, North-based NGOs are often over-represented in the developing world, arguably skewing power relations and undermining CSOs based in developing countries, whose goals often involve systemic reform and a rejection of Northern-constructed simplistic campaigns.

Beyond the historical origins influencing the ways in which particular CSOs operate, a major factor in the effectiveness of CSOs is the internal cohesion of the organization. Sometimes CSOs struggle for internal cohesion because they represent a diverse group of actors with competing interests (Grant, 2012; Hilgersom, 2012) or have weak leadership capacity (Strutt \& Kepe, 2010). One group of actors that has caused both internal cohesion and discord are teachers' unions (Eickelberg, 2012; Van Der Plaat, 2012a,b; Hilgersom, 2012). Involving teachers' unions may at times hinder state support and symbolic legitimacy because it involves a

\footnotetext{
${ }^{3}$ Whether increased involvement of NGOs in education is beneficial has been a topic of scholarly debate (see, for example, the special issues on NGOs in Current Issues in Comparative Education from 1999 and 2009).

3 Verger and Novelli (2012) note that "'civil society' is a very broad and contested category," including a variety of "organizations such as international and local NGOs, trade unions, community-based organizations, grassroots movements, independent research institutes, etc." (p. $3)$. In keeping with this definition, CSOs can, with the exception of social movements, also be termed non-governmental organizations. We thus employ these two terms interchangeably in this paper, except when we refer to social movements.
} 
group critical of government policies; however, forgoing the involvement of teachers' unions excludes a group that often has valuable perspectives on schooling. Finding an agreement or internal cohesion among the competing interests often means excluding some groups from the organization.

The relationship between CSOs and national-level education actors also partly determines the effectiveness of CSOs. National relationships can be complicated for CSO because CSOs "have potentially critical or destabilizing viewpoints" (Mundy, et al., 2012, p. 488), such as those advanced by some teachers' unions, as described above. The maintenance of such relationships with national-level actors can be difficult when CSOs are perceived (rightly or wrongly) as a conduit for international actors or ideas to influence national level policymaking (Rappleye, 2011). NGO coalitions can also be a conduit through which national governments operate. It is possible for governments to try to use CSOs as a means through which state power and discourse work, and they can attempt to do so in a way which is in competition with how international organizations pursue a version of so-called educational "development." As such, CSOs often must strike a balance between working with the state and working for the state, sometimes erring too far on one side and thus compromising their effectiveness.

\subsection{Analytic Framework}

In order to study CSEF's impact on NEP and NEP's impact on national level education policy making, we draw on an analytic approach elaborated by Verger et al. (2012). This approach is appropriate for our purposes because we want to understand how NEP engaged in various interrelated contexts and processes as it sought to impact education politics and policymaking at the national level. The analytic framework takes account of the relevant aspects and dimensions of the political context, institutional setting, and organizational processes. The benefit of this framework is that it provides a way to understand and assess aspects of the case that have hindered and/or helped to engender a range of specific outputs and general outcomes. For our purposes, it will be important to distinguish between the characteristics of the institutional setting before and after the arrival of funds from the CSEF to NEP in Cambodia. That is, in order to accurately depict the impact of the CSEF on NEP's advocacy, it will be necessary to first note the state of NEP prior to the influx of support from the GCE through the CSEF.

Figure 1 visually displays our analytic framework. This diagram depicts how the GCE and associated regional networks of civil society actors interact in the context of the CSEF. While this interaction will be explained in more detail in the findings section, we want to point out here that national coalitions fit into this schematic diagram in the area of core processes (i.e., output processes of advocacy, lobbying, and campaigning; learning processes of operational research and adapting advocacy tools to specific contexts; and cooperation processes of capacity building; see figure 1). For example, NEP carries out advocacy, lobbying, campaigning, research, and capacity building in Cambodia with the assistance of the steering and support activities and processes that are managed by the GCE and the regional civil society networks. Within this larger arrangement, we will focus on CSEF's effects on NEP's organizational capacity and internal processes and the ways that these effects helped to realize broader outcomes and impacts regarding education politics and policymaking. 
Figure 1: Steering, Core, and Supportive Processes

in the context of the Civil Society Education Fund

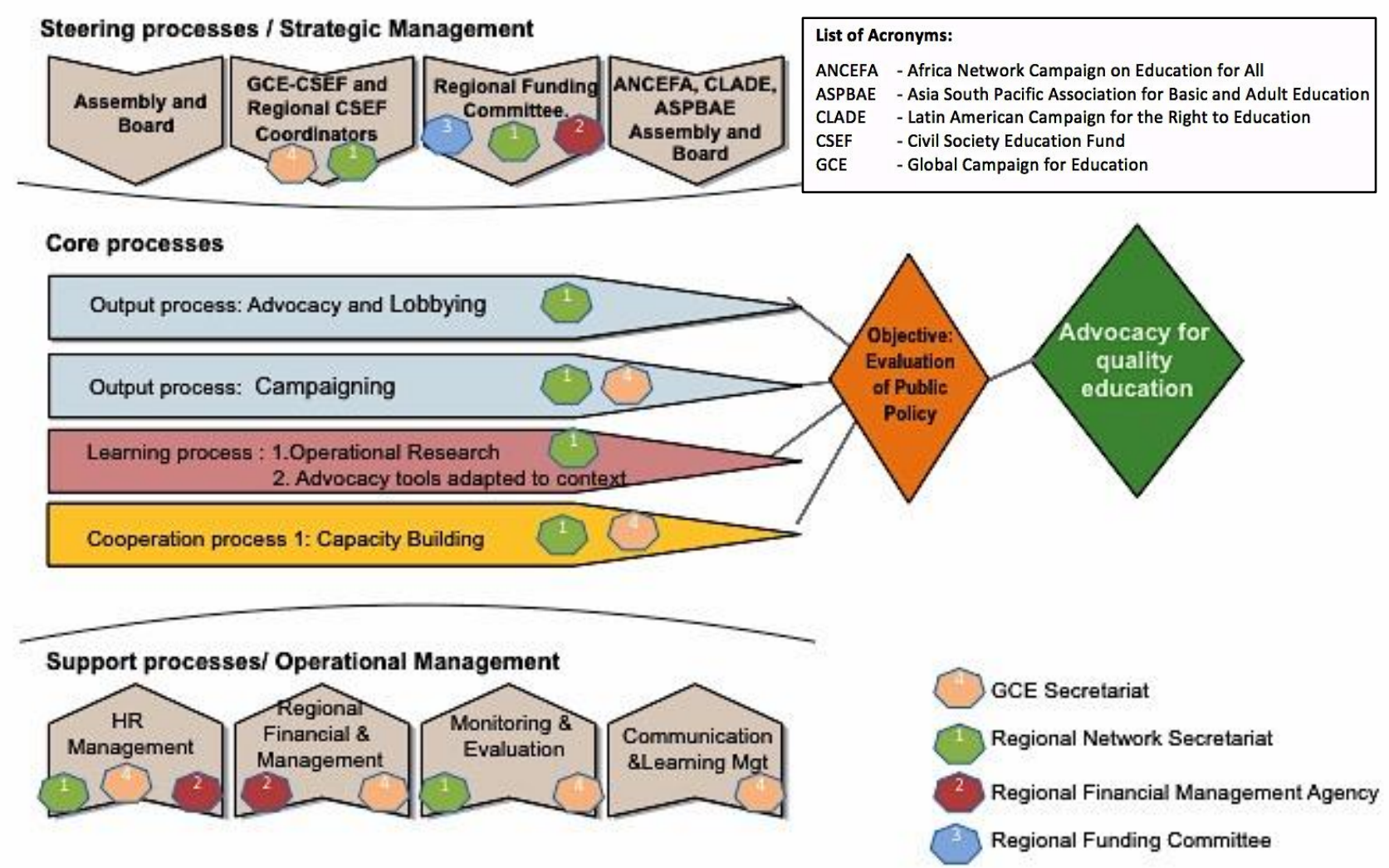

Source: Verger et al., 2012

As can be seen in Figure 1, the core processes of the advocacy coalitions should contribute to advocating for quality education. Distinguish among outputs, outcomes, and impact is important. In keeping with standard definitions (Russ-Eft \& Preskill, 2009), while outputs refer to particular deliverables related, for example, to advocacy and campaigning (e.g., number of workshops or number of radio advertisements), outcomes refer to relevant changes in behavior and perception. In the present case, these changes include, but are not limited to:

[the development of] new capacities and knowledge(s) that have been generated under the CSEF, the way this knowledge has been integrated in the coalition's everyday work, the way the CSEF has contributed to strengthening the coalition's institutional setting, the way it has strengthened the legitimacy and credibility of the coalition and, as a consequence, the extent to which the [national education coalition] is more active in education policy spaces and processes (such as the Local Education Groups, the Poverty Reduction Strategies, the elaboration and monitoring of the National Education Plans, and in the media) and, finally, the policy impact that derives from all of this (Verger et al., 2012, p. 18).

Policy impact - that is, policy changes in education resulting from CSO advocacy — is one of the broadest forms of outcome to which the CSEF intends to contribute. But as the above quote makes clear, even in the absence of policy impact, the CSEF can be considered to have been 
successful to the extent that it contributed to a CSO's general capacity, perceived legitimacy, and overall participation in strategic policy spaces.

\subsection{Context of Cambodia ${ }^{4}$}

The present level of civil society engagement in the Cambodian education sector must be viewed in relation to the political situation emerging in the 1990s, following the genocidal conflict of the 1970s and control of the government by Vietnam in the 1980s (Kiernan, 1982). Despite installing democracy in 1993, strong authoritarian and patrimonial or clientelistic tendencies are still evident in society (McCargo, 2005; Pak et al., 2007; Springer, 2013). Cambodia has had the same Prime Minister (Hun Sen, from the Cambodian People's Party) since 1985, and the country is known for limited freedoms of press (Reports Without Borders, 2014). NGOs therefore tend to be cautious when critiquing the actions and performance of those in power (Bandyopadhyay \& Khus, 2013). That said, NGOs and other development partners have had increased latitude to operate in Cambodia, since the early 1990s (Dy \& Ninomiya, 2003). ${ }^{5}$ NGOs in the education sector have enjoyed considerable freedom, likely due to their tendency to be less confrontational and critical of the government (Edwards \& Brehm, 2015). The Cambodian Independent Teachers' Association has not only been excluded from enjoying similar freedom but also has been oppressed by the ruling party. NGOs in the education sector also gained a stronghold in the wake of the re-establishment of the education sector in the 1980s, when the capacity of the central government was still extremely weak. The current political climate, then, is in many ways milder in the education sector than in the government as a whole, but some groups, such as the teachers' union, remain marginalized. In spite of hostile government measures against NGOs generally, there exists a strong sense of good-will toward education NGOs, which have typically been viewed as key to provide vital public services and to meet the Millennium Development Goals and the EFA goals, especially given that the government of Cambodia is heavily dependent on external funding, both generally (Springer, 2011) and for education (UNESCO, 2011).

Three other aspects of the Cambodian case merit attention in order to understand recent contextual constraints and enabling factors of CSO participation on the national level (Edwards $\&$ Brehm, 2015). First, the government still relies on the capacity and technical expertise of outside organizations, though governmental officials have undoubtedly improved in these areas. Second, in the years following the 2008 general elections, the CPP has become the sole actor in collaboration with NEP. Prior to this, there were two political parties represented at the highest levels of the Ministry of Education, Youth, and Sport (MoEYS), making it difficult for NEP to work well with either one because most suggestions would engender a negative reaction from the other. However, since the CPP replaced MoEYS staff who were members of the main opposition party, NEP has been able to engage more openly and effectively with leaders within the MoEYS, and without fear of repercussion. (Although this is at the expense of opposition parties, further entrenching power in the hands of the CPP.) The third and final change in the governmental context relates to the first. Specifically, there is a new wave of officials slowly reaching the

\footnotetext{
${ }^{4}$ In accordance with the focus of this paper, this section focuses on the political context and the political factors that affect education policymaking and politics. For more on characteristics of the Cambodian education sector itself (e.g., related to funding, access, pedagogy, dropout, etc.), see Kitamura, Edwards, Chinnh and Williams (2015).

${ }^{5}$ As of 2011, there was a total of 3492 NGOs registered in Cambodia (Bandyopadhyay \& Khus, 2013).
} 
higher ranks of the MoEYS. This handful of individuals represents the next generation of intellectuals and highly trained functionaries in government. This group typically received training outside of Cambodia (e.g., in Japan, Australia, and the United States), and is more open to research, criticism, and working with NGOs.

In addition to the above-mentioned issues, challenges arise in the intersections between government, NGOs, and development partners, since these actors have become intertwined when it comes to education governance (Edwards \& Brehm, 2015). One notable example is the Deconcentration and Decentralization initiative, led by UNICEF and begun in 2007, which has sought to create joint development partner and government planning spaces in all 24 departments across the country, although they have tended to be operational only in those provinces where UNICEF provides funding (UNICEF, n.d.). The initiative illustrates UNICEF's level of influence on governmental decisions. Not only does UNICEF offer direct budget support, but it also participates in upstream policy discussions. UNICEF is also the only development partner with provincial-level offices. UNICEF's level of governmental influence helps explain why it is an important ally for NEP, having helped to found NEP in 2002. Other influential development partners in the education sector include the European Commission, the Swedish International Development Association, and the World Bank. UNESCO is also involved in certain aspects of the education sector, but is seen as neutral, and does not contribute much monetarily. The World Bank has a strong link with the government, as well as a comparatively large budget, while USAID and the Japan International Cooperation Agency (JICA) primarily dedicate themselves to project implementation.

In general, the government wants NGOs to work with development partners through coordination forums, such as the Education Sector Working Group (ESWG) and the Joint Technical Working Group (JTWG) (Edwards \& Brehm, 2015). The principal mission of both groups is to promote aid effectiveness through joint programming, information sharing, provision of technical support to the MoEYS, and more. The ESWG meets monthly and has been chaired by the UNESCO since 2011 (prior to that by UNICEF). Its primary mission is to collect feedback from members, and communicate these back to the government. The JTWG, which can be understood as the ESWG plus the government, is chaired by the Minister of the MoEYS, and meets quarterly. While the government accepts NEP involvement in ESWG or JTWG, they do not want NEP to be a separate/critical voice. This is particularly problematic as the government has not wanted to tackle its weaknesses - either generally or in the education sector, at least not until the arrival of the most recent minister of education (Dr. Hang Chuon Naron) in 2013 (after the completion of this research), who is much more open to hearing critical commentary (Chhinh, 2015). It is the government's view that development partners and NGOs should work with the priorities of the government, and not critique the current system. With this background and analytical framework in mind, we now turn to the methods used in this research.

\section{Methods}

Data collection for this study occurred in Cambodia during July and August 2012, and was funded by the GCE (Verger et al., 2012). ${ }^{6}$ The information gathered came from 36

\footnotetext{
${ }^{6}$ Only the lead author was involved in the case study conducted for GCE, though the findings presented here reflect on the understanding of all the authors. The involvement of additional researchers in the preparation of the present piece has helped to reduce bias and to strengthen the analysis of the article despite research funding from the GCE.
} 
interviews with 38 different individuals and document analysis of internal NEP documents. Interviews were one of the chosen methods of data collection because they can, when performed correctly, provide insights into the intricacies and dynamics of the CSEF and its effects specifically as well as their ability to reveal the interaction of relevant stakeholders and political actors more generally. Interviewees were purposefully targeted based on their involvement in, and knowledge of, education reform and the role of civil society in the context of Cambodia. Interviews occurred with such actors as the staff and leadership of NEP; representatives of NEP member organizations; representatives of multi- and bi-lateral development partners (e.g., UNESCO, World Bank, JICA, and Asian Development Bank [ADB]); international NGOs; policymakers; leadership from the MoEYS); representatives of media (radio and TV stations); and members of academia.

In seeking out relevant interviewees, a wide net was cast not only to ensure that a thorough understanding was gained of the political context in which NEP was embedded but also to ensure that a multi-dimensional understanding was obtained of NEP's actions and impact. A careful effort was made to seek out key individuals from within and outside this organization who possessed first-hand knowledge of NEP's institutional setting and organizational processes, as well as its degree of success in achieving the various outcomes at the heart of the CSEF program. Interviews occurred at times and in locations that were convenient for participants.

Based on the data collected, this case study attempts to (a) show how NEP's organizational processes were impacted by the CSEF, given the characteristics of the political context and NEP's pre-existing institutional setting; (b) indicate the extent to which the expected outcomes were achieved; and (c) explain which factors facilitated or inhibited the realization of those outcomes. Findings on these issues were produced by transcribing interviews and then systematically reviewing not only those transcripts but also the internal documents collected from NEP. Data was analyzed to look for information that pertained to each aspect of the analytic framework as well as to the larger political-economic context within Cambodia, in order to understand the ways that this context constrained and/or enabled the CSEF, NEP, processes of policymaking, and the involvement of relevant political actors in them. Data from interviews and document analysis were triangulated by organizing the information collected by theme, which were based on the dimensions in the analytic framework.

\section{Findings: The Case of NEP}

NEP was officially constituted as a membership organization in 2002, registered with the Ministry of Interior in 2006, and signed a memorandum of understanding with the MoEYS in 2007. By 2015, NEP had approximately 100 member organizations and considers itself an important actor in educational governance, representing the voices of civil society (NEP, 2015). Although the trajectory of NEP may indicate straightforward progress, the organization almost closed in 2008 for reasons primarily related to leadership, as explained below. In order to understand how NEP managed to survive, to be recognized as a pillar in educational governance, and to contribute to education politics in Cambodia, we need to unpack its strategic use of CSEF support.

\subsection{New NEP leadership and the internal effects of the CSEF}

Interviewees stated that prior to the CSEF, NEP "didn't have a voice" in the education sector, that the organization was "defective," that it "almost disappeared" (CAM6, 13-14), and that it was saved thanks to assistance from Volunteer Service Overseas (VSO), an international 
federation of NGOs that recruits volunteers to work in developing countries for two years, and from the Board of Directors, which is made up of representatives from seven international organizations (CAM19). These struggles were often attributed to NEP leadership in its formative years, which were marked by low levels of cooperation and communication with the MoEYS.

The leadership of NEP changed shortly before participation in the CSEF began. In October 2008, a new director started, under whose leadership NEP began to exhibit new behaviors, such as: more active participation in MoEYS policy discussions; more professional presentation methods when interacting with development partners and the MoEYS; more sensitivity in communication with the MoEYS, particularly around critical findings and critical feedback; production of internal policies for NEP (e.g., staff policy, financial policy, organizational charter); and development of a long-term plan. The new leadership was a major factor why NEP was successful in developing a close relationship with government and development partners. Moreover, the new director used the funding from the CSEF in ways that promoted NEP's agenda. These issues will be unpacked in this section.

NEP's budget increased because of the CSEF. In 2006, NEP had a total budget of US $\$ 34,870$, in 2007 , US\$89,141, and in 2008 , US $\$ 99,100$. Of the US $\$ 99,100$ that NEP received in 2008, a large majority of it (US\$91,484) came from five sources: UNICEF (US\$28,280), the German Catholic Bishops' Organization for Development Cooperation (MISEREOR) (US\$39,780), Education Watch (US\$8,562) and Asia South Pacific Association of Basic and Adult Education (ASPBAE) (US\$14,862). During the following year (2009), due to funding from the CSEF, the budget increased by almost 100\%. An audit for the period from August 2009 to June 2010 shows that NEP received US\$97,919 from the CSEF alone, making it the largest single donor. This trend continued from July 2010 to December 2011, when the CSEF contributed a total of US $\$ 134,444$.

With a larger budget came the ability to hire additional staff members. In 2009, there were only 5 people working in NEP: one position for leadership (the director of NEP), two positions for programs (research and coordination), one for finance, and one for administrative issues, in addition to one volunteer from VSO. The following year, as a direct result of the CSEF funding, NEP hired three more personnel: a research officer, an education officer, and a finance officer/accountant. By 2012, CSEF funding had ensured a total of 15 staff members. As a direct result of the CSEF funds, NEP hired a research coordinator in 2009; it also created a research advisory board. NEP's research activities have played a key role in their success, as discussed further below.

The CSEF also involved NEP in regional bodies. As part of the CSEF program, regional coalitions hosted small secretariats that helped national NGO coalitions to prepare papers for funding committees, to ensure proper reporting and accounting, to promote experience sharing, and to offer capacity building support (Verger et al., 2012). For NEP, the corresponding regional coalition was ASPBAE, which coordinated 1-2 regional workshops each year, focusing on capacity building and information sharing. In November 2010, for example, ASPBAE organized a workshop on financial management and the Asia Regional Pre-General Assembly GCE gathering. Three NEP staff members and the director of NEP's board attended. ASPBAE staff also visited NEP to provide steering support.

The CSEF funding and regional involvement enhanced the capacity of NEP, improving the core processes of the organization. With an infusion of resources and support from the CSEF, and with the additional staff members hired, NEP could strategically engage in advocacy, lobbying, campaigning, research, and capacity building. The director of VSO, a long-time ally of 
NEP, made a series of comments that speak to the internal effects of the CSEF on NEP and the ways these effects enhanced NEP's legitimacy:

The capacity of NEP has increased significantly in terms of number of staff and confidence in skills. ... NEP profiles have increased significantly for both national and international for advocacy. [They have a] large ... team with specific skills and experience on programmes. Staff skills and knowledge have been increased and are confident to do their jobs with less support from outside, [including] mobilizing existing skills to support specific needs, for example: research, campaigns, forums (CAM23, 2-3).

In the next section, we address another outcome to which the CSEF contributed: the multiple forms of recognition achieved by NEP.

\subsection{Additional outcomes: Recognition in multiple forms}

After three years of support from the CSEF, a major outcome for NEP came in the form of recognition. This is important because in 2009, before the arrival of CSEF funds, NEP had no voice at the national level of policymaking. Since the analytic framework indicates that program outcomes refer to relevant changes in behavior and perception, the extent to which NEP is now recognized as an actor in the education sector cannot be understated. Firstly, they began to be recognized for research and analytic abilities. A representative of the ADB commented that NEP made "sharp observations" (CAM8, 6), and an interviewee from the World Bank indicated that he cited NEP studies (CAM6, notes). Secondly, NEP is recognized by the government as the coordinator of education NGOs in Cambodia. On this point, the MoEYS told one local NGO: "No, don't talk to us. Talk to NEP. NEP will talk to us" (CAM11, notes). A third form of recognition is as the preeminent voice of civil society in education. As the Director of the Planning Department within the MoEYS said, "We cannot deal and work individually with all NGOs. We have to work with NEP, and NEP can further work with all NGO under NEP" (CAM5, p. 27). Additionally, whenever any committees are formed by the government for dialogue on policy, NEP has been invited (CAM19, int1, 17). Fourthly, NEP sees itself as an integral and trustworthy partner of the MoEYS. Two quotes make this clear. The first is from an NEP staff member, while the second is from NEP's Director.

Gradually NEP has become more stable and has done more activity, so the Ministry started to really trust us as a representative of civil society, ... so they invite us to all meetings that the Ministry conduct, so it seems like even the Minister, even the Education Ministry, the Annual Education Retreat, NEP has been invited to provide feedbackwhat is the progress? challenges? And NEP has been invited to join the Annual Education Congress, teacher policy discussion-everything from the Ministry of Education in Cambodia. So, our profile has been raised to some extent. We are recognized by the Ministry. (CAMFG2, 11).

For example, ... they put the name of NEP in the small working group as well as in the technical working group for developing teacher policy. In the retreat, they say ok, NEP have to be there. In the committee they formed to prepare for the education congress, they also have NEP there. And the midterm review ..., they also invite NEP. So every time they have meeting or consultation or develop any new policy or revise policy or something the name of NEP always appears in the list of invitation. (CAM19, int1, 21). 
The fifth indication of institutional recognition is in the view of NEP as being one of three main pillars of education policy making. The interview conducted with the Secretary of State for Education made this view clear: he considers NEP (as a representative of civil society more broadly) to be one of the pillars of the education sector (outside of government), along with the UN family of organizations and bi-lateral donors. Accordingly, key actors within the MoEYS recognize NEP as a contributor of valuable suggestions. The MoEYS staff believe that NEP can stay in touch with the large number of primary schools (more than 6,800) better than it can. Thus, the Director of the Primary Department of the MoEYS values NEP suggestions and inputs because they are practical and rooted in experience at the school level (CAM7, 7-10). Similarly, the director of the Planning Department stated the following: "They [NEP] have very good practical recommendation from practical perspective" (CAM5, 10). One example mentioned by this director was NEP's suggestion to focus on community engagement in education.

\subsection{Substantive impact: Policy engagement and stakeholder capacity building}

The CSEF has also strengthened NEP's impact in terms of policy and stakeholders' participation in education governance since 2009 (Edwards \& Brehm, 2015). Although not with regularity, there is evidence that NEP has the ability to host high profile events at which they present the results of their research. One example of this was on May 8, 2012 when NEP held an all-day conference to present the results of research that it had done on early childhood care and education. The event was attended by 150 stakeholders from the government, development partners, and the education sector. Another event that stands out was an all-day event on July 4, 2012 where a research report was presented on the impact of incentives on teacher motivation. It was attended by a broad cross-section of stakeholders.

There has been improvement in NEP's stature and ability to advocate, due in large part to their permanent seats on the ESWG and JTWG, which NEP was able to attain during the first quarter of 2012 through their increased recognition and contributions (Edwards \& Brehm, 2015). Moreover, as a result of the experience gained over the past three years (doing research, participating in the ESWG and JTWG, interacting with development partners and the MoEYS in a variety of settings, presenting researching findings, and facilitating a range of training activities), NEP has the confidence to contribute policy feedback to the government and to make requests to give presentations of its research directly to the JTWG, which is the highest level for education policy dialogue with the government and development partners.

Not only do the government and development partners seek NEP's feedback, but NEP is also able to invite representatives of the government and development partners to its events. These connections show government and development partners how NEP arrives at its input for policy discussions, which fosters additional trust and positive rapport. Beyond making room for the participation of NEP in the ESWG, the development partners now also recognize the importance of input from NEP's members and so allow time for NEP to collect that feedback before proceeding. Additionally, on several occasions, NEP has been sought out for comments by development partners. For example, the head of UNESCO asked NEP for feedback on the speech that she gave at the opening ceremony for the mid-term review of the Education Strategic Plan Lastly. NEP has also begun to cooperate closely and regularly with the directors of departments within the MoEYS, such as the Director of the Primary Education Department.

There are multiple examples of NEP involvement in MoEYS policy-related events. One key example is the Education Retreat, a high-level annual event attended by 20 stakeholders 
from within and outside government to discuss priorities for the education sector. By virtue of its attendance, NEP was able to communicate directly, and often informally, with the small group of high-level education officials who were in attendance. NEP was recognized as having provided good feedback at this event (CAM6). NEP attended in 2009 and 2011; no retreat was organized in 2010.

Another example is the annual Education Congress, a forum attended by around 1,000 education sector stakeholders to look at "what works, what doesn't, and what should be improved" (CAM13, 7). NEP was involved in the planning and delivery of the education congress. The result of the congress was a report with analysis on the progress made in the education sector during the previous year.

By participating in the events that the MoEYS holds for the purpose of gathering feedback, NEP has been able to contribute pertinent policy-related information and suggestions to the government. Through such forums - together with NEP's involvement in the ESWG and JTWG - NEP has influenced at least one issue on the short list of priorities for the MoEYS, according to a high-level interviewee from VSO: "Through research and advocacy, the Ministry of Education has included the reduction of parental costs in the priority list of the Education Strategic Plan" (CAM23, 5). Importantly, it should be noted that, beyond the studies that NEP conducts itself, NEP is able to channel into its discussions with government the knowledge and feedback that it gains from its member organizations. To that end, it will be essential that NEP continues to learn from its members, since they are in touch with the reality of education at the local level. However, beyond learning, an area for future growth for NEP is actively supporting its member organizations when it comes to gathering, documenting, and presenting local-level knowledge.

Relatedly, through the CSEF, NEP dedicated itself to capacity building of other civil society actors (Edwards, 2012). Aside from hiring personnel and carrying out research, the funds distributed to NEP by the CSEF have primarily gone to the "Community Engagement in Quality Education" (CEQE) project, which began in 2009. This project involved providing assistance to NGOs working in 16 schools across three provinces with activities ranging from building libraries and purchasing reading material to arranging enrolment campaigns. In addition, participating NGOs also attempted to assist in the capacity building of school directors, provincial officers of education, and district officers of education. The idea behind this pilot project was to improve the quality of education and to improve the engagement of the community in these schools, in addition to learning lessons on how to build capacity at the provincial, district, and community levels that could then be shared and disseminated to member NGOs in other provinces, not to mention to the MoEYS and development partners (CAMFG1). As a result of the CEQE project and the documented lessons that NEP learned, the head of the Primary Education Department mentioned at a regional meeting in front of hundreds of attendees that he sought to meet with NEP about drafting new roles and responsibilities for school support committees (CAM20, notes).

NEP has chosen a collaborative and non-confrontational approach to advocacy, typically avoiding topics that might be interpreted as a critique of the government. In June of 2009 NEP produced an advocacy strategy that was intended to guide the organization from 2010-2013. According to this document, the advocacy strategy of NEP should focus on early childhood education, valuing teachers, informal school fees, and community engagement in quality education. Noticeably, half of these advocacy issues (i.e., early childhood education and community engagement) correspond to issues that are of importance to the MoEYS. 
Despite the successes NEP had using CSEF funding — and the CSEF's successes influencing NEP - some areas within NEP remained under the influence of the government. For example, NEP's research topics were frequently derived from issues that the MoEYS identified as being most salient. NEP did not choose issues that the government perceived as sensitive (e.g., corruption), ${ }^{7}$ and NEP submitted a letter to the MoEYS detailing research that they wished to carry out before commencing activities. Additionally, the teachers' union was purposefully excluded from joining NEP because of concerns that their involvement would upset the government. Given this context, it could be argued that NEP became a conduit through which the state operated in its efforts to be recognized and perceived legitimate by elite policymakers. Instead of working with the state on educational reform, NEP worked for the state, entrenching power relationships that discourage dissent and criticism.

\section{Discussion and Conclusion}

The CSEF allowed NEP to address the shortages that it was experiencing in terms of core capacity prior to 2009. The new director helped in these efforts. Noticeably, this is similar to Van der Plaat's (2012a) finding in Zambia where the NGO coalition had a leader whose personal characteristics helped them to work across a diversity of opinions in the coalition, in addition to ensuring that the coalition had clear systems, frameworks, and strategies that are communicated to its members. If NEP's director had not been willing to change the organizations method of engaging the MoEYS and development partners, it is likely that the successes would have been stifled during the period when the CSEF funded NEP.

More broadly, the impact of the CSEF can be explained by looking at developments in NEP's organizational processes and institutional setting. As noted, the former refers to steering, support and core processes. Supporting processes include those routines that relate to management, finance, monitoring, evaluation, communication, and learning. Although central to organizational operation, they were not, in fact, greatly affected by CSEF funding. While some progress was made in the area of membership communication and consultation (by having more frequent meetings and by more regularly soliciting input from the membership), interviewees within NEP actually spoke to the weakness of systems related to finance, self-monitoring, and self-evaluation. Moreover, what progress was achieved was not only a result of the CSEF but rather also of the new director of NEP, who began his tenure a few months before NEP began participation in the CSEF. On this point, one should remember that NEP is a small organization. The director focused on expanding and strengthening the organization with funding from the CSEF, and was able to hire additional staff who helped to increase the capacity. But, due to its small size, NEP is necessarily dependent on the director to some extent.

Steering processes look at how an organization details goals, sets strategic vision, reviews implementation activity, and makes investment decisions. These areas were affected by the the CSEF in that NEP, in order to receive funding, had to align at least some of its goals and activity with the priorities and purposes of the CSEF program, which was intended to enhance advocacy that would lead to progress towards EFA. The preconditions for funding drove successful steering processes. While NEP was already an advocacy organization, it was necessarily locked into - though not restricted to - the prerogatives of the GCE around EFA and its other initiatives while receiving CSEF funding. Thus, although NEP's participation in the CSEF meant

\footnotetext{
${ }^{7}$ For more on corruption in the education sector, see Brehm and Edwards (2014); more generally, see Springer (2011).
} 
that it was prompted to participate in Global Action Week, ${ }^{8}$ World Teachers' Day, and International Literacy Day, in addition to lobbying for EFA goals as part of its advocacy, NEP was also able to engage in other activities unrelated to the CSEF (e.g., when it conducted research on the impact of incentives on teacher motivation). More broadly, it should be remembered that a central purpose of the CSEF is to contribute to long-term development of participating civil society organizations by improving underlying organizational capacity and support processes, as further discussed below.

Lastly, and most importantly, are core processes, which, for their part, are made up of advocacy activities and related tasks, such as "campaigning, training, technical capacity building, research, data management, the diagnoses of education problems, and the articulation of demands and policy solutions" (Verger et al., 2012, p. 17). In this area, NEP improved significantly as a result of the CSEF's funding. The strengthening of NEP's core processes was a result of the overall buttressing of the institutional setting that the CSEF funding made possible. The CSEF funding and regional support increased NEP's human and economic resources, which positively impacted institutional capacity (through the hiring of additional key personnel). Moreover, the CSEF participation led to more predictable funding (even if only for three years), not to mention increased contributions by other international organizations because of the legitimacy with which NEP was imbued through their endorsement by the GCE.

Figure 2 reflects the way that the CSEF impacted NEP through funding and support from regional bodies (described earlier in the paper, in the section on the internal effects of the CSEF). It does so by highlighting the fact that the resources and benefits from the CSEF flowed into and affected NEP's institutional setting (i.e., organizational structure, leadership, financial wellbeing) and (to a certain degree) steering processes — both of which then augmented its core processes, which are the lynchpin of to the success of any advocacy organization. These developments contributed, in turn, to the outcomes and impacts discussed in the previous section. Hence, while CSEF funding did not augment each set of relevant organizational processes to the same degree, and while the CSEF as a program thus has room for improvement, a key insight here is that this program, as an extension of transnational civil society, was able to support a national level coalition of education-related NGOs and, in so doing, strategically contributed to the coalition's achievement of key outcomes and impacts that range from recognition to policy input to policy influence. On the negative side, the ascendance of NEP to becoming a key pillar in educational governance required implicit support of the government's anti-dissent stance towards groups such as the teachers' union. Seen within the larger context of the global governance of education, the case of NEP can be understood as a particularly successful example of trans-national collaboration geared towards enhancing the role of national civil society in education policy and politics. Yet it is crucial that we underscore the political context in which NEP was located and the fact that NEP had to employ its capacity and engage its core processes in ways that were calculated according to the constraints of their setting.

\footnotetext{
${ }^{8}$ According to the GCE website, "Global Action Week is one of the major focal points for the education movement. It provides every national and regional education campaign with an opportunity to highlight one area of the Education For All agenda and make targeted efforts to achieve change on the ground, with the added support of education campaigners and millions of members of the public worldwide joining together for the same cause" (Global Campaign for Education, 2016).
} 
Figure 2: Process of CSEF Impact in Case of NEP

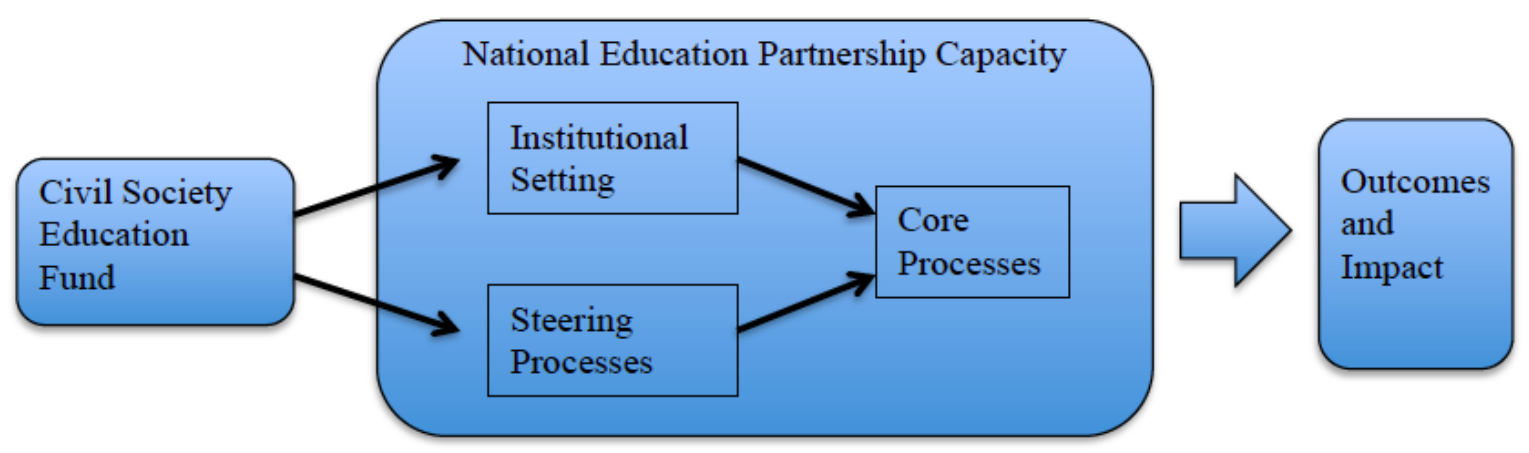

Source: Authors

A number of points can be raised around lessons learned. First, when an organization such as NEP is suffering from a lack of finances and credibility, the infusion provided by a CSEF-type program can have a multiplying effect. The present study suggests that this is so as long as the program is used to address weaknesses in capacity that the recipient organization is facing — and, preferably, over a multi-year time horizon. ${ }^{9}$

Second, when a government is not receptive to confrontational and antagonistic advocacy methods, it may be more advantageous to participate in established (albeit often governmentcontrolled) processes in order to gain the trust of the MoEYS and the development partners. Over time, as the government and development partners come to appreciate and rely on the roles that an organization such as NEP performs (e.g., policy-centered research, data collection on education NGOs, practical and grassroots-level information sharing, feedback presentation, etc.), the NGO coalition may have opportunities to meaningfully, directly, and non-threateningly contribute to education policy reform (perhaps even through closed-door meetings if the topics are sensitive and likely to be met with rancor if broached publicly). The downside with this approach is that CSOs become complicit in the government's marginalization of certain groups and opinions.

Third, in addition to participating in national-level policy dialogue in forums such as the ESWG and JTWG, it is important that coalitions build relationships with department heads (and technical specialists) within the MoEYS to make it possible to influence the details of policy formulation and implementation. Pursuing various avenues of input and impact is essential, particularly since CSOs tend to have a "marginalized role in decision making" (Strutt \& Kepe, 2010, p. 370), even when they gain a seat at the proverbial table, as in the case of NEP.

Fourth, and extending the above point, national education NGO coalitions need to be cautious and vigilant so that they are not co-opted by the government. It is easy to become complacent upon learning to operate within the boundaries established as acceptable by the authorities. Efforts at influencing the agenda of the government must continue, but in a way that is measured, consistent, and convincing, without triggering a reactionary response that may

${ }^{9}$ While the present study focused on the 2009-2011 time period, NEP has received funding from CSEF in subsequent years. For more on how NEP has used CSEF funds beyond 2011 - and with what impact—see Institute for Development Impact (2015). 
preclude civil society from future participation. CSOs must carefully walk the line between participation in government or development partner-lead processes that, by their nature, legitimize those processes, and participation that pushes for more socially just policies, though this is often a delicate balance (Edwards \& Brehm, 2015).

Fifth, managing these tensions can be more difficult when teachers' unions are involved, but excluding them comes at a cost. Indeed, NEP has not had a relationship with the Cambodian Independent Teacher's Association precisely because of the difference in strategy regarding engagement with the government. Unlike NEP, this Teacher's Association directly and aggressively confronts the government in the media and through protests. As a result, the Teacher's Association and its members are persecuted by the government. NEP believes that it cannot have a relationship with both the Teacher's Association and the government, because it would prevent progress with the government through NEP's strategy of calculated engagement. NEP is not unique in this situation: CSOs in many countries confront this same dilemma when it comes to the decision of whether (and how) to engage teachers' unions or social movements while also working with ministerial officials. By marginalizing teachers' unions, however, CSOs oppress a large constituency in education, namely teachers, who have direct experience in schools. This constituency is a valuable group to include when it comes to educational advocacy.

A final lesson is associated with implementation. That is, if a coalition is going to engage with the CSEF (or a similar source of funding) to finance a community-level project - as NEP did with the CEQE - it should make sure that it systematically captures its own experience. Moreover, the coalition should do this while the project is ongoing so that it can later share with other NGOs and coalitions strategies related to, and difficulties associated with, increasing the capacity of member NGOs who then attempt to increase the capacity of community members to engage in local advocacy and school governance.

This case has shown that progress in advocacy, involvement, legitimacy, and impact is possible for national NGO coalitions when receiving transnational support and through the employment of certain strategies, even in repressive conditions. Yet, a lingering tension concerns the position of national NGO coalitions between national governments and international organizations. Future research will be necessary to understand better how CSOs have managed to gain additional autonomy and to maintain that autonomy in the face of the pressures associated with external funding and the government's own vision of the role of civil society in the education sector.

An additional tension concerns the relationship between national coalitions and their local membership. While the present paper touched on this issue in connection with NEP's CEQE project, this relationship should be further examined, both in Cambodia and other countries, especially since the local membership can be a source of strategic involvement for civil society that complements the efforts of the national coalition. Or, indeed, local NGOs can be a source of pressure that ensures that the national coalition itself does not become complacent and is not co-opted by the national government or development partners. This is most clearly at issue when it comes to teachers' unions involvement with the NGO coalition. By extension, a central question to ask will be: How can — or to what extent should — transnational civil society support not only national coalitions and local NGOs around international targets but also around the priorities and needs of those local actors?

It is also essential to conduct research on how CSOs have been able to successfully work together with teachers' unions and social movements, both within and across countries. This is an important area since these actors may have memberships and access to resources that can help 
NGO coalitions to reach the critical mass necessary to achieve policy impact or to secure broader concessions from governments. Pooling these resources and building on each other's capacity could help to strengthen the position of CSOs vis-à-vis international organizations and the work that the latter do at the country level and at the level of constructing the global education agenda. Given Education International (the global federation of teachers' unions) was among the founding members of GCE, it would make sense that national-level teachers' unions are involved in any intervention of civil society.

While the issues raised here will be perennially relevant in the context of the global governance of education, they will be particularly salient in the near future, as CSOs at all levels mobilize around the post-2015 development agenda.

\section{References}

Bandyopadhyay, K. K., \& Khus, T. C. (2013). Changing Civil Society in Cambodia: In Search of Relevance, Development in Practice, 23 (5-6), 665-677.

Bendaña, A. (2006). NGOs and social movements: A North/South divide? Civil Society and Social Movements Programme Paper No. 22, Geneva: UN Research Institute for Social Development. Retrieved from http://www.unrisd.org/80256B3C005BCCF9/(httpAuxPages)/4F7CC72852DD23EBC12 571D1002B45AD/\$file/Bendana.pdf Accessed on January 14, 2016.

Brehm, W. \& Edwards Jr., D.B. (2014). "The many spaces of learning: Private tutoring and post2015 Education for All," Norrag News, 50, 56-58. Available at: http://www.norrag.org/fileadmin/Full\%20Versions/NN50.pdf

Chhinh, S. (2015). The way forward for education reform in Cambodia. In Y. Kitamura, D. B. Edwards Jr., S. Chhinh, \& J. Williams (Eds.), The political economy of schooling in Cambodia: Issues of equity and quality. New York, NY: Palgrave MacMillan.

Civil Society Education Fund (2015). Biannual progress and supervision report, January-June 2015. Paris: UNESCO. Retrieved from http://www.globalpartnership.org/sites/default/files/2015-06-unesco-csef-progresssupervision-report.pdf.

Davies, R. \& Dart, J. (2005). The "Most Significant Change" (MSC) technique: A guide to its use. Retrieved from http://mande.co.uk/docs/MSCGuide.pdf

Dy, S. S., \& Ninomiya, A. (2003). Basic Education in Cambodia: The Impact of UNESCO on Policies in the 1990s, Education Policy Analysis Archives 11 (48), 1-20.

Edwards Jr., D.B. (2012). CSEF evaluation: Cambodia. Universitat Autónoma de Barcelona. Available at: http://www.globalpartnership.org/content/civil-society-education-fundindependent-evaluation-country-reports

Edwards Jr., D. B., \& Brehm, W. (2015). "The emergence of Cambodian civil society within global educational governance: A morphogenetic approach to agency and structure," Journal of Education Policy, 30 (2), 275-293.

Eickelberg, A. (2012). Framing, Fighting and Coalitional Building: The Learnings and Teachings of the Brazilian Campaign for the Right to Education. In A. Verger \& M. Novelli (Eds.), Campaigning for "Education for All": Histories, Strategies and outcomes of Transnational Advocacy Coalitions in Education. Rotterdam, Netherlands: Sense Publishers.

Grant, L. (2012). National Coalition for Education India: The Second Freedom Struggle Against Illiteracy. In A. Verger \& M. Novelli (Eds.), Campaigning for "Education for All": 
Histories, Strategies and outcomes of Transnational Advocacy Coalitions in Education. Rotterdam, Netherlands: Sense Publishers.

GCE. (2016). Global action week. Available at: http://www.campaignforeducation.org/en/globalaction-week

Hilgersom, S. (2012). Advocating Public Education in Indonesia. The Role of Organizational Processes and Critical Reflection within E-net for Justice. In A. Verger \& M. Novelli (Eds.), Campaigning for "Education for All": Histories, Strategies and outcomes of Transnational Advocacy Coalitions in Education. Rotterdam, Netherlands: Sense Publishers.

Hoop, J. (2012). People Power for Education: Civil society participation in the Philippine educational politics. In A. Verger \& M. Novelli (Eds.), Campaigning for "Education for All": Histories, Strategies and outcomes of Transnational Advocacy Coalitions in Education. Rotterdam, Netherlands: Sense Publishers.

Hoppers, W. (2009). Participatory practices in policy-making: Negotiating democratic outcomes or manoeuvring for compliance? International Journal of Educational Development, 29(3), 250-259. doi: 10.1016/j.ijedudev.2008.02.004

Institute for Development Impact. (2015). Case study report - NEP Cambodia. In Volume II: Country case studies reports: Independent evaluation of the Civil Society Education Fund (CSEF) Programme 2013-2015 for the Global Campaign for Education. Washington, D.C. Available http://www.campaignforeducation.org/docs/csef/reports/CSEF\%202013-

2015\%20EXTERNAL\%20EVALUATION\%20REPORT\%20\%20VOLUME\%20II\%20CASE\%20STUDIES.pdf

Kamat, S. (2004). The privatization of public interest: theorizing NGO discourse in a neoliberal era. Review of International Political Economy, 11(1), 155-176. doi: 10.1080/0969229042000179794

Kiernan, B. (1982). William Shawcross, Declining Cambodia, Bulletin of Concerned Asian Scholars, 18 (1), 56-63.

Kitamura, Y., Edwards Jr., D. B., Chhinh, S., \& Williams, J. (Eds.). (2015). The political economy of schooling in Cambodia: Issues of equity and quality. New York: Palgrave MacMillan.

Klugman, B. (2011). Effective social justice advocacy: a theory-of-change framework for assessing progress. Reproductive Health Matters, 19(38), 146-162.

Mayne, J. (2008). Contribution analysis: An approach to exploring cause and effect ILAC Brief 16.

McCargo, D.(2005). Cambodia: Getting Away with Authoritarianism?Journal of Democracy16(4), 98-112. The Johns Hopkins University Press. Retrieved January 14, 2016, from Project MUSE database.

Mundy, K. (2012). The Global Campaign for Education and the Realization of "Education For All". In A. Verger \& M. Novelli (Eds.), Campaigning for "Education for All": Histories, Strategies and Outcomes of Transnational Advocacy Coalitions in Education. Rotterdam, Netherlands: Sense Publishers.

Mundy, K., Haggerty, M., Sivasubramaniam, M., Cherry, S., \& Maclure, R. (2010). Civil society, basic education, and sector-wide aid- insights from Sub-Saharan Africa. Development in Practice, 20(4/5), 484-497. doi: 10.1080/09614521003763046RoutledgePublishing 
Mundy, K., \& Murphy, L. (2001). Transnational advocacy, global civil society: Emerging evidence from the field of education. Comparative Education Review, 45(1), 85-126.

NEP. (2015). About NEP. 2015, from http://www.nepcambodia.org/index.php option=com_content\&view=article\&id=89\&Itemid=137\&lang=en

Pak, K., Horng, V., Eng, N., Ann, S., Kim, S., Knowles, J., \& Craig, D., (2007). Accountability and neo-patrimonialism in Cambodia: A critical literature review. Working Paper 34. Phnom Penh: Cambodian Development Resource Institute.

Rappleye, J. (2011). Catalysing educational development or institutionalising external influence? Donors, civil society and educational policy formation in Nepal. Globalisation, Societies and Education, 9(1), 27-49. doi: 10.1080/14767724.2010.513517

Reports Without Borders. (2014). World Press Freedom Index. Avilable at: https://rsf.org/index2014/en-index2014.php Accessed: January 13, 2016.

Russ-Eft, D., \& Preskill, H. (2009). Evaluation in Organizations: A Systematic Approach to Enhancing Learning, Performance and Change. New York, NY: Perseus Books.

Springer, S. (2011). Articulated Neoliberalism: The Specificity of Patronage, Kleptocracy, and Violence in Cambodia's Neoliberalization. Environment and Planning, A 43, 2554-2570.

Strutt, C., \& Kepe, T. (2010). Implementing Education for All-Whose agenda, whose change? The case study of the Ghana National Education Campaign Coalition. International Journal of Educational Development, 30(4), 369-376. doi: 10.1016/j.ijedudev.2009.12.008

UNESCO (2011). Education and fragility in Cambodia. Retrieved from http://toolkit.ineesite.org/toolkit/INEEcms/uploads/1150/CS2_INEE_Working_Cambodi a.pdf

UNICEF. (n.d.). Our partners: Swedish International Development Cooperation Agency. Retreived from: http://www.unicef.org/cambodia/12685_20714.html

Van Der Plaat, F. (2012a). Advocating EFA in Zambia: A Case Study of Civil Society's Struggle for Equal Rights for Education. In A. Verger \& M. Novelli (Eds.), Campaigning for "Education for All": Histories, Strategies and outcomes of Transnational Advocacy Coalitions in Education. Rotterdam, Netherlands: Sense Publishers.

Van Der Plaat, F. (2012b). Striving for Education for All in Ghana: the role and impact of the Ghana National Education Campaign Coalition. In A. Verger \& M. Novelli (Eds.), Campaigning for "Education for All": Histories, Strategies and outcomes of Transnational Advocacy Coalitions in Education. Rotterdam, Netherlands: Sense Publishers.

Verger, A., \& Novelli, M. (2012). Introduction to Civil Society Coalitions and Educational Advocacy: Theoretical and Methodological Insights. In A. Verger \& M. Novelli (Eds.), Campaigning for "Education for All": Histories, Strategies and Outcomes of Transnational Advocacy Coalitions in Education. Rotterdam, Netherlands: Sense Publishers.

Verger, A., Rambla, X., Bonal, X., Bertomeu, N., Fontdevila, C., Garcia-Alba, À., .. . Koolwijk, T. v. (2012). Regional and National Civil Society Education Funds, CSEF: Evaluation Report (Vol. 4): Globalization Education and Social Policies. Retrieved from http://www.campaignforeducation.org/docs/csef/CSEFev_FINAL_REPORTv4 complete.pdf

White, H., \& Phillips, D. (2012). Addressing attribution of cause and effect in small n impact evaluations: towards an integrated framework 3IE Working Paper 15. 